\title{
Study of the Influence of Safety Factors by Performing Factor Analysis
}

\author{
Abhijith Jacob $^{\# 1}$, Jenson Joseph ${ }^{\# 2}$, Mahesh Rengaraj ${ }^{\# 3}$ \\ ${ }^{\# 1}$ P. G. Scholar, ${ }^{\# 2}$ Assistant Professor, ${ }^{\# 3}$ Associate Professor \\ Department of Mechanical Engineering, M G University \\ SCMS School of Engineering and Technology, \\ Karukutty, Ernakulam, India
}

\begin{abstract}
Averages of 6,000 people die every day as a result of work-related accidents or diseases, totally more than 2.2 million work-related deaths per year. About 350,000 deaths out of this mortality are from workplace accidents and more than 1.7 million are from work related diseases. An effective safety analysis requires attention to human factors as well as system components which makes risky or safe situations in technical components. Paying attention to human factors, organizations with high reliability can recognize hazards before occurrence. One of the most important methods for achievement to this purpose is using leading criteria such as safety climate or safety culture. This is an study report on the study of the influence of safety factors by performing factor analysis at an electrical industry The questionnaire survey was conducted among 60 employees, involving employees from all levels of the organisation. The data collected was subjected to principal component factor analysis with varimax rotation using SPSS software. The results reveal that four distinct factors namely management commitment, worker knowledge, environmental safeness and validation together explains $56.6 \%$ of the total variance. Internal consistency (Cronbach Alpha) across items in each of the four factors and that of the total were found to be above 0.7 and thus acceptable.. The questionnaire contained 30 questions to measure the perceptions of the employees about the management practices. Descriptive statistics and correlations of the studied variables were first analyzed. Confirmatory factor analysis was used to verify the reliability of the management practices. Regression analysis was conducted to test the goodness of fit of the various models.
\end{abstract}

Keywords - industrial safety, worker knowledge, management commitment, factor analysis.

\section{INTRODUCTION}

People and management systems are two components of each organization that together make safety climate and safety culture at organization. The macro ergonomics domain deals with the overall design of work systems. Since the early days of the discipline, organizational design and management factors have sometimes been considered in ergonomic analysis and design, but it was not until the beginning of the 1980s that the area began to receive formal recognition as a distinct sub discipline of ergonomics. The term of safety culture gained its first official use in an initial report into the Chernobyl accident.

More specifically, safety culture is seen as a subfacet of organizational culture. The concept of safety culture has its origin in the social and behavioral psychology of the 1950's and 1960's that came to the fore in the organizational psychology, organizational behavior, and management literature of the 1980's. As the safety culture is a subset of the overall organizational culture and subset of organizational factors, denoting the extent to which upper level management demonstrates positive and supportive safety values, attitudes and behaviors. It is one of the most stable and substantial forces within organizations, shaping the way members think, behave, and approach their work. Zohar (1980) coined the term safety climate in an empirical investigation of safety attitudes in an Israeli manufacturing, and defined it as

"A summary of molar perceptions that employees share about their work environments. As many of the definitions of safety culture and safety climate have common elements, safety climate may reflect the underlying culture of the work-group or organization, although its focus is actually much narrower than safety culture". During the study the majority of the accidents were resulted from (i) lifting of objects; (ii) oven heating; (iii) checking; (iv) welding (v) lamination cutting and (vi) falling objects

\section{A. Organisational study}

Organizational studies encompass the study of organizations from multiple viewpoints, methods, and levels of analysis. Whenever people interact in organizations, many factors come into play. Modern organizational studies attempt to understand and model these factors. In the past, the inspection of major hazard plant has typically focussed on the technical aspects of safety. In recent years the emphasis has shifted towards organisational and management factors, with concepts such as "safety culture" and "safety management systems" receiving increasing attention. This 
can in part be attributed to inquiries into major accidents over the past decade having identified weaknesses in organisations as a primary underlying cause (Linda et al., 1995). In their study Simard et al., (1995) estimated the influence of various micro-macro organisational factors on the propensity of workgroups to take safety initiatives. Later studies showed that organizational and social factors do influence safety performance (e.g., Cox and Flin, 1998; Donald and Canter, 1994; Glendon and Stanton, 2000; Guldenmund, 2000; Vinodkumar and Bhasi, 2009). Even though a clear consensus is yet to evolve on the dimensions to be included in the organisational factors of industrial safety, it is widely accepted that they are good predictors of safety related outcomes (Simard et al., 1995).

\section{B. The present study}

The study was conducted in an electrical industry in Kerala, India.

The objectives of the study are:

- To determine the organisational factors that influence industrial safety in the industry using principal component factor analysis.

- To identify perceptions of employees about the organisational factors.

- To evaluate the association between perception of employees and actual safety performance in terms of injury experiences.

\section{MATERIALS AND METHOD}

\section{A. Description of case study plant}

This study was carried out at an electrical industry located in India. The case study plant is a public sector undertaking under the Government of Kerala, India. There are approximately 410 employees working at 8 departments of the plant. As per the company any harm, hurt, wound or damage to the body is considered as an injury/accident. A Pareto plot was drawn for the causes of accidents .Among 54 accidents reported during the year of 2012, majority were contributed by the lamination cutting department.

\section{B. Description of subject population}

The organisation hierarchy broadly comprises of frontline, middle line and managerial posts. Frontline employees are the workers primarily handling the shop floor activities and include designations of skilled worker and technical assistant. Officer and engineer designation comes under the middle line employees who directly monitors and controls the shop floor activities. The managerial post is entrusted with the duty of administration of particular departments. Majority of the employees are temporary workers and lacks the privileges of the permanent employees.

Among the respondents, $21 \%$ belonged to the age group of 20-30 years, $27 \%$ belong to the age group of 31-40 years,
$35 \%$ belonged to age group of $41-50$ and $17 \%$ belonged to the age group of 51-60 and $20 \%$ of the respondents had less than 5 years experience, $43 \%$ had 5-10 years experience, $17 \%$ had 11-20 years of experience and about $20 \%$ had above 20 years of experience. In order to ensure good response rate it was decided to collect the questionnaire back immediately if possible. Thus questionnaire was distributed to employees during leisure time. Shift of the workers changed every two weeks. Since the study spanned a period of two months, people working in all shifts could participate ensuring a complete cross-section.

\section{Survey instrument}

From review of related literature and theory, a 30 item questionnaire covering areas of safety awareness, safety training, management commitment, work environment, work processes and procedures, employee attitude and involvement was prepared. The content and substance of most of the questions were taken from previous questionnaires of Linda et al. (1995), Simard et al. (1995), Vinodkumar and Bhasi, (2009), Vivek V. Khanzode et al.(2012) and from various other publications. The contents of the draft questionnaire were discussed with safety professionals from the industry and senior professors in management studies to ensure face validity. A pilot survey was conducted on a selected sample of workers to get the feedback about the clarity of items. Those items with reliability measure less than 0.6 were dropped from the instrument. After considering each item in detail, necessary changes were made by simplifying, rewording, removing and replacing some of the items.

It was decided to give the questions in English as well as the local language Malayalam. Respondents were asked to give their preference on a five points Likert scale (strongly disagree, disagree, neither disagree nor agree, agree and strongly agree) in order to evaluate the subject's agreement with each item.

The two pages questionnaire ready for administration consisted of two parts. Four demographic questions about gender, age, educational qualification and years of experience constituted the first part. The 30 statements related to safety formed the second part. Space was provided beside each statement to mark the preference.

\section{Analyses}

The analyses were conducted as per the objectives of the study outlined in introduction. Accordingly, the analyses comprise three phases. First, factor analysis was used to factor the items and determine hidden dimensions, if any. Further, to test the differences in perception of employees among the significant demographic factors, analysis of variance (ANOVA) was conducted. Finally, to examine the relationship between organisational factors and work injury experience, linear regression was modelled with due 
consideration of the significant factors obtained through earlier phases of analyses.

\section{RESULTS}

\section{A. Factor analysis}

The data collected were used to develop a factor model with varimax rotation using SPSS statistical program. The inter item correlation obtained was satisfactory. Internal consistency, Cronbach's alpha was calculated for the items, resulting in a reliability measure of 0.741 which is above the acceptable limit of 0.6 (Hair et al., 1995). The factor loading cut-off was fixed at 0.4.The data are fit for the factor analysis, as indicated by the Kaiser-Meyer-Olkin (KMO) measure of sampling adequacy value of 0.771 . Bartlett Test of Sphericity is also significant $(x 2=550.75, \mathrm{df}=215, \mathrm{p}=$ $0.000)$. A 4-factor model is retained from a set of combinations tested, which together explained $56.599 \%$ of the total variance.

The results of the factor analysis are presented in Table 1. The four factors identified are named as (a) management commitment, (b) worker knowledge, (c) environmental safeness and (d) validation. Reliability measures for individual factors range from 0.67 to 0.81 , indicating adequate internal consistency.

Table 1. Results of factor analysis showing factor name, no. of items, factor loadings, \% variance explained and Cronbach alpha

\begin{tabular}{ccccc}
\hline Factor name & Items & Factor loadings & \% variance explained & Cronbach alpha \\
\hline Management commitment & 8 & $0.55-0.869$ & 21.489 & 0.74 \\
Worker Knowledge & 7 & $0.525-0.779$ & 14.498 & 0.8 \\
Environmental Safeness & 5 & $0.587-0.803$ & 9.348 & 0.71 \\
$\quad$ & 5 & $0.639-0.795$ & 6.007 & 0.69 \\
\hline
\end{tabular}

Table 2. Results of correlation analysis

\begin{tabular}{|c|c|c|c|c|c|}
\hline & Total accidents & Management commitment & Worker knowledge & Environmental safeness & Validation \\
\hline Total accidents & 1 & .116 & $-.074^{*}$ & -.032 & .019 \\
\hline Management commitment & .116 & 1 & .061 & -.177 & -.081 \\
\hline Worker Knowledge & $-.274^{*}$ & .061 & 1 & -.051 & .153 \\
\hline Environmental Safeness & -.032 & -.277 & -.051 & 1 & $.294^{*}$ \\
\hline Validation & .019 & -.081 & .153 & $.294^{*}$ & 1 \\
\hline \multicolumn{3}{|c|}{$\begin{array}{l}\text { * correlation is significant at the } 0.05 \text { level } \\
\text { B. Regression analysis } \\
\text { To evaluate the association between perception of } \\
\text { employees and actual safety performance in terms of injury } \\
\text { experiences a regression model was formed and tested. } \\
\text { Initially analysis was done by correlating the factor scores } \\
\text { with reported injury rate. Results of correlation analysis are } \\
\text { given in table } 2 \text {. The results reveal that most of the } \\
\text { organisational factors are negatively correlated with total } \\
\text { accidents. Also there is significant positive correlation } \\
\text { between most of the factors. }\end{array}$} & \multicolumn{3}{|c|}{$\begin{array}{l}\text { management commitment, worker knowledge, } \\
\text { environmental safeness and validation was selected as the } \\
\text { independent variables. The model was run stepwise and } \\
\text { three models were obtained. The model which explained } \\
\text { largest percentage of variance }(80.7 \%) \text { was selected. The } \\
\text { results of which are given in table } 3 \text {. } \\
\text { C. Correlation Analysis } \\
\text { Correlation measures the degree of association between two } \\
\text { or more variables. It can be positive, negative or zero. A } \\
\text { quantitative measure of the linear association between the } \\
\text { two variables is given by Karl Pearson correlation } \\
\text { coefficient. The correlation coefficient can take value } \\
\text { between }-1 \text { and }+1 \text {.in case it takes a value of }+1 \text {, it is called a }\end{array}$} \\
\hline
\end{tabular}


perfect positive correlation and if takes a value of -1 , it is called perfect negative correlation.

Table 3. Results of regression analysis

\begin{tabular}{|c|c|c|c|c|c|}
\hline \multicolumn{6}{|c|}{ Coefficients } \\
\hline \multirow[t]{2}{*}{ Model 1} & \multicolumn{2}{|c|}{ Unstandardized Coefficients } & \multirow{2}{*}{$\begin{array}{c}\begin{array}{c}\text { Standardized } \\
\text { Coefficients }\end{array} \\
\text { Beta }\end{array}$} & \multirow[t]{2}{*}{$\mathbf{T}$} & \multirow[t]{2}{*}{ Sig. } \\
\hline & B & Std. Error & & & \\
\hline (Constant) & 6.565 & 1.475 & & 4.450 & .000 \\
\hline Worker Knowledge & -.203 & .094 & -.274 & -2.166 & .034 \\
\hline
\end{tabular}

Table 4. Anova reults

\begin{tabular}{|c|c|c|c|c|c|c|}
\hline \multicolumn{7}{|c|}{ ANOVA } \\
\hline Model & & $\begin{array}{l}\text { Sum of } \\
\text { Squares }\end{array}$ & Df & Mean Square & $\mathrm{F}$ & Sig. \\
\hline \multirow[t]{3}{*}{1} & Regression & 17.699 & 1 & 17.699 & 4.689 & $.034^{\mathrm{b}}$ \\
\hline & Residual & 218.884 & 58 & 3.773 & & \\
\hline & Total & 236.583 & 59 & & & \\
\hline
\end{tabular}

a. Dependent Variable: Total accidents

b. Predictors: (Constant), Worker knowledge

\section{DISCUSSION AND CONCLUSIONS}

One of the key interests of this study was to determine organisational safety structure in an electrical industry. The dimensions included in the initial questionnaire preparation phase were chosen from various previous studies conducted in a variety of industries. The four factors obtained after the factor analysis were seen individually in other reports (Linda et al., 1995, Simard et al., 1995). Management commitment, (Zohar, 1980; Cox and Cheyne, 2000) is often taken as a significant factor in organisational and safety climate studies. Many of the factors are comparable with the results of other studies conducted in various industries and could be concluded that some generic factors do exist in organisational safety studies.

The relative importance of the independent variables is obtained by the absolute value of the standardized regression coefficients given in table 3. The absolute value of standardized coefficient for worker's knowledge is 2.166 .
This indicates that worker's knowledge has most influence in the accidents occurring.

An important feature of this study is its reliability and constructs validity. All the factors have a negative correlation with the total number of accidents. This is in tune with the findings of Donald and Canter (1994). The regression results confirm that the factors are indeed predictors of self reported accidents. Further investigation was carried out to find out the difference in perception between different groups of individuals.

Previous researches have argued that no fixed set of safety dimensions exists and cultural differences between populations have an influence on the safety management. It is also possible that the factors that influence safety structure within one industry may not be valid in another because organizations differ in management style and safety regulations resulting in different safety perceptions which are then reflected in different factor structures. The main dimensions and items included while preparing the 
questionnaire also influence the safety climate factor structure. The study was conducted acknowledging the above limitations and constraints.

In this study it is revealed that all of the four management practices have good reliability suggesting that the survey items were appropriate indicators of their respective construct. It is revealed that worker's knowledge factor has more influence in the safety. The study also demonstrated that the perceptions of safety management practices influence the rate of accidents. By improvising these practices the rate of accidents can be reduced to a good extent. The result of this study also highlighted the need of safety promotion policies and safety training to the workforce. The results look encouraging and promising as they posses good reliability. In a country where safety is not given the priority it deserves, any change in work culture and mindset will have to overcome considerable resistance from all quarters.

\section{ACKNOWLEDGEMENTS}

The authors gratefully acknowledge the support and cooperation provided by the respondents and management of the foundry studied. The authors would like to thank everyone who with their constructive comments helped to improve the quality of the paper.

\section{REFERENCES}

[1] S.A. Basha, J. Maiti, 2013. Relationships of demographic factors, job risk perception and work injury in a steel plant in India. Safety Science 51, 374381

[2] Cox, S., Flin, R., 1998. Safety culture: philosopher's stone or man of straw? Work and stress 12 (3), 189201.

[3] Cox, S.J., Cheyne, A.J.T., 2000. Assessing safety culture in offshore environments. Safety Science 34, 111-129.

[4] Glendon, A.I., Stanton, N.A., 2000. Perspectives on safety culture. Safety Science 34, 193-214.

[5] Guldenmund, F.W., 2000. The nature of safety culture: a review of theory and research. Safety Science $34,215-257$.

[6] Hair, J.F., Anderson, R.E., Tatham, R.L., Black, W.C., 1995. Multivariate data analysis with readings, fourth ed. Prentice-Hall, New Jersey.

[7] Dr Linda J Bellamy, Bridget A Leathley, and W. Huw Gibson, 1995. Organisational Factors and Safety.
[8] Marcel Simard, Alain Marchand, 1995. A multilevel analysis of organisational factors related to the taking of safety initiatives by work group, Safety Science 21, 113-129

[9] M.N. Vinodkumar, M. Bhasi, 2009. Safety climate factors and its relationship with accidents and personal attributes in the chemical industry. Safety Science 47, 659-667

[10] M.N. Vinodkumar, M. Bhasi, 2010. Safety management practices and safety behaviour: Assessing the mediating role of safety knowledge and motivation. Accident Analysis and Prevention 42, 2082-2093

[11] Vivek V. Khanzode, J. Maiti, P.K. Ray, 2012. Occupational injury and accident research: A comprehensive review. Safety Science 50 1355-1367

[12] Zohar, D., 1980. Safety climate in industrial organizations: theoretical and applied implications. Journal of Applied Psychology 65, 96-102. 